\title{
Pediatric in-hospital emergencies: real life experiences, previous training and the need for training among physicians and nurses
}

\author{
Ronny Lehmann ${ }^{1 *} \mathbb{D}$, Anke Seitz ${ }^{1}$, Jochen Meyburg ${ }^{1}$, Bettina Hoppe ${ }^{1}$, Georg Friedrich Hoffmann', \\ Burkhard Tönshoff ${ }^{1}$ and Sören Huwendiek ${ }^{2}$
}

\begin{abstract}
Objective: Pediatric emergencies challenge professional teams by demanding substantial cognitive effort, skills and effective teamwork. Educational designs for team trainings must be aligned to the needs of participants in order to increase effectiveness. To assess these needs, a survey among physicians and nurses of a tertiary pediatric center in Germany was conducted, focusing on previous experience, previous training in emergency care, and individual training needs.

Results: Fifty-three physicians and 75 nurses participated. Most frequently experienced emergencies were respiratory failure, resuscitation, seizure, shock/sepsis and arrhythmia. Resuscitations were perceived as being particularly precarious. Team collaboration and communication were major issues arising from previous emergency situations, but perceptions differed between physicians and nurses. Regarding previous training, physicians were accustomed to self-directed learning, whereas nurses usually attended practical courses. Both physicians and nurses rated themselves as having moderate levels of knowledge and skills for pediatric emergencies, though residents reported the significantly lowest preparedness. Both professions reported a high need for training of basic procedures and emergency algorithms, physicians even more than nurses.
\end{abstract}

Keywords: Pediatrics, Emergency medicine, Interprofessional education, Needs assessment, Continuing medical education

\section{Introduction}

Several studies have revealed major deficits in emergency preparedness among professional staff [1-6]. Most serious errors in critical care occur because of poor communication or collaboration, rather than individual mistakes $[7,8]$. For example, one prospective observational study by Hunt et al. conducted pediatric emergency simulations with mock codes. Of the teams involved, $75 \%$ deviated from current resuscitation guidelines, and all demonstrated communication errors [9].

The importance of team training to improve team behavior is more and more highlighted [7] using

\footnotetext{
*Correspondence: ronny.lehmann@med.uni-heidelberg.de

1 Department of Pediatrics I, Center for Pediatrics and Adolescent Medicine, Im Neuenheimer Feld 430, 69120 Heidelberg, Germany Full list of author information is available at the end of the article
}

simulation-based training as standard educational approach [10-12]. Team training allows shared expertise and perspectives based on group knowledge and skills [13]. On-site simulation training can massively increase opportunities for learning for local staff when embedded in the hospital routine [14]. Educational strategies need to be optimized in such interprofessional training programs to improve patient outcomes [1,7].

Little is known about whether previous experiences with emergencies, previous training, and individual needs for pediatric emergency training differ between physicians and nurses or how these should be taken into account when developing interprofessional team training. Therefore, we surveyed the physicians and nurses of a tertiary pediatric center in Germany on these issues as the first step in developing an in-house team training program. For this needs assessment, our goal was 
to identify frequent and/or critical in-house emergency situations, and aspects which support or impede them. Further we wanted to know how educational strategies differed between physicians and nurses, in order to appraise acceptance for different teaching methods that could be used. Also, concrete training objectives (procedures, algorithms) needed to be determined by assessing individual demands.

We hypothesized similar experiences with emergencies by both, physicians and nurses, but with differing perspectives depending on professional roles. We expected acceptance for self-directed learning as limited especially for a non-academic profession like nursing, and the available time for additional hands-on courses as limited in particular among physicians. Furthermore, we expected comparable high needs for training of basic as well as advanced procedures among medical and nursing staff.

\section{Main text \\ Methods \\ Participants}

We invited all the physicians and nurses of the tertiary Center for Pediatrics and Adolescent Medicine, Heidelberg, Germany, to participate in this survey. At the time of the survey which was conducted in autumn 2010, 127 physicians and 410 nurses were employed. Participation was voluntary and anonymous.

\section{Evaluation instruments}

The survey was structured into four sections: basic data of the participants, previous experience of in-house emergencies, previous training on emergencies, and individual needs for such training. For details of used items see Table 1. Questions were either open, allowing multiple answers, or requested agreements on a 5-point Likert scale from 1 (totally disagree) to 5 (totally agree). Selections of training needs were taken from current guidelines [15], published questionnaires on pediatric emergency preparedness [16-20], and interviews with in-house experts. The survey forms were pilot-tested with physicians and nurses in think-aloud studies before implementation, and revisions were made to ensure clarity and response process validity [21]. We used a webbased survey platform, as well as paper-based survey forms distributed to all possible participants. Where appropriate, the nurse-directed survey form asked for assistance in the procedures as some procedures are only performed by physicians (especially venipuncture is a physician activity at the study site). Trauma management was not addressed, as this is provided by the local pediatric surgery department.

\section{Data analysis}

Free-response answers in the sections on previous emergency experiences and previous training were analyzed using content analysis; keywords were determined in order to assess frequencies of answer categories [22]. Previous training was compared using Chi square tests for comparable answer categories. Self-assessed levels of adequate knowledge and skills on pediatric emergencies were compared using a onefactor analysis of variance (ANOVA) with the betweensubject factor 'profession and qualification level' and the dependent variables 'knowledge' and 'skills'. Least significant difference (LSD) post hoc tests were conducted where appropriate, including Bonferroni corrections for multiple comparisons. Statistical differences for individual training needs were calculated using t-tests for between-group comparisons. IBM SPSS Statistics Version 24 (IBM Corporation, Armonk, NY) was used for analysis, with an $\alpha$ level of 0.05 .

Numerical results are given as mean \pm standard deviation, or percentages. For open questions, the five most frequent responses are presented, followed by their percentage of all given answers in brackets.

\section{Results \\ Participation and basic data}

Twenty-six residents, 12 specialists and 15 consultants participated in the survey (together $41.7 \%$ of the center's medical staff), as well as 64 nurses and 11 head nurses (18.3\% of the nursing staff), see Table 1 . The mean ages of nurses and physicians were comparable ( $36.2 \pm 11.6$ vs. $32.7 \pm 4.8$ years); however, the mean duration of clinical practice of nurses was almost twice as long as that of physicians $(15.3 \pm 10.7$ vs. $8.2 \pm 7.0$ years).

Experienced critical or emergency situations Physicians, 92 responses:

1. Respiratory failure (21.7\%);

2. Resuscitation (14.1\%);

3. Seizure (14.1\%);

4. Shock and sepsis (7.6\%) and arrhythmia (7.6\%).

Nurses, 117 responses:

1. Respiratory failure (31.6\%);

2. Resuscitation (20.5\%);

3. Seizure (12.8\%);

4. Shock and sepsis (11.1\%);

5. Arrhythmia (10.3\%). 
Table 1 Survey form and numerical results

\begin{tabular}{|c|c|c|c|c|}
\hline & Item & Medical staff & Nursing staff & \\
\hline & & $\begin{array}{l}\mathrm{N}=53(41.7 \% \text { of medical house } \\
\text { staff) }\end{array}$ & $\begin{array}{l}\mathrm{N}=75(18.3 \% \\
\text { of nursing house } \\
\text { staff })\end{array}$ & \\
\hline \multirow[t]{4}{*}{ Basic data } & Age (years) & $32.7 \pm 4.8$ & $36.2 \pm 11.6$ & \\
\hline & Gender & $\begin{array}{l}65.8 \% \text { female } \\
34.2 \% \text { male }\end{array}$ & $\begin{array}{l}96.4 \% \text { female } \\
3.6 \% \text { male }\end{array}$ & \\
\hline & Clinical practice (years) & $8.2 \pm 7.0$ & $15.3 \pm 10.7$ & \\
\hline & Level of qualification & (Resident, specialist or consultant) & (Nurse or head nurse) & \\
\hline \multirow[t]{4}{*}{ Previous experience } & $\begin{array}{l}\text { Which critical or emergency situations did } \\
\text { you experience so far in the hospital? }\end{array}$ & (Free text) & (Free text) & \\
\hline & $\begin{array}{l}\text { In which of them did you feel the most } \\
\text { insecure? }\end{array}$ & (Free text) & (Free text) & \\
\hline & What went good in these situations? & (Free text) & (Free text) & \\
\hline & $\begin{array}{l}\text { What could have been better in these situa- } \\
\text { tions? }\end{array}$ & (Free text) & (Free text) & \\
\hline \multirow[t]{2}{*}{ Previous training } & $\begin{array}{l}\text { How did you acquire knowledge about man- } \\
\text { aging emergencies so far? }\end{array}$ & (Free text, Fig. 1) & (Free text, Fig. 1) & \\
\hline & $\begin{array}{l}\text { How did you acquire practical skills (like } \\
\text { bag-valve-mask ventilation, intubation etc.) } \\
\text { so far? }\end{array}$ & (Free text, Fig. 1) & (Free text, Fig. 1) & \\
\hline \multirow[t]{22}{*}{ Individual needs assessment } & $\begin{array}{l}\text { I have adequate knowledge to handle pediat- } \\
\text { ric emergencies }\end{array}$ & (Figure 2) & (Figure 2) & \\
\hline & $\begin{array}{l}\text { I have adequate skills to handle pediatric } \\
\text { emergencies }\end{array}$ & (Figure 2) & (Figure 2) & \\
\hline & I need to have more training on... & & & $p$-value \\
\hline & Pediatric basic life support & $4.8 \pm 0.5$ & $4.5 \pm 0.8$ & 0.011 \\
\hline & Pediatric advanced life support & $4.5 \pm 0.7$ & $4.2 \pm 0.9$ & 0.119 \\
\hline & Bag-valve-mask ventilation & $4.8 \pm 0.5$ & $4.4 \pm 0.9$ & 0.002 \\
\hline & Endotracheal intubation & $4.3 \pm 0.8$ & $3.7 \pm 1.2$ & 0.005 \\
\hline & Intravenous access & $4.1 \pm 1.3$ & $3.2 \pm 1.4$ & $<0.001$ \\
\hline & Central venous access & $3.8 \pm 1.2$ & $3.4 \pm 1.2$ & 0.065 \\
\hline & Intraosseous access & $3.9 \pm 1.2$ & $3.3 \pm 1.3$ & 0.005 \\
\hline & Newborn life support & $4.6 \pm 0.8$ & $3.4 \pm 1.3$ & $<0.001$ \\
\hline & Management of foreign body aspiration & $4.7 \pm 0.6$ & $4.1 \pm 1.0$ & $<0.001$ \\
\hline & Management of unconsciousness & $4.7 \pm 0.6$ & $4.2 \pm 0.9$ & $<0.001$ \\
\hline & Management of respiratory distress & $4.7 \pm 0.7$ & $4.0 \pm 1.0$ & $<0.001$ \\
\hline & Management of anaphylactic reactions & $4.6 \pm 0.8$ & $4.2 \pm 0.9$ & 0.004 \\
\hline & Management of seizures & $4.7 \pm 0.7$ & $4.0 \pm 1.0$ & $<0.001$ \\
\hline & Management of arrhythmia & $4.5 \pm 0.7$ & $3.8 \pm 1.2$ & 0.001 \\
\hline & Management of shock & $4.6 \pm 0.7$ & $4.2 \pm 0.9$ & 0.008 \\
\hline & Management of metabolic emergencies & $4.4 \pm 0.8$ & $3.2 \pm 1.3$ & $<0.001$ \\
\hline & Team communication & $4.3 \pm 0.9$ & $4.0 \pm 1.1$ & 0.167 \\
\hline & Which objectives for training are missing? & (free text) & (free text) & \\
\hline & $\begin{array}{l}\text { I would like to participate in an interprofes- } \\
\text { sional course (physicians and nurses) on } \\
\text { pediatric emergencies. }\end{array}$ & $4.7 \pm 0.6$ & $4.6 \pm 0.8$ & 0.443 \\
\hline
\end{tabular}

Mean \pm standard deviation or percentages. Agreements in the individual needs assessment on Likert scale from 1 (totally disagree) to 5 (totally agree) 
Situations feeling the most insecure Physicians, 37 responses:

1. Resuscitation (32.4\%);

2. Airway and respiration management (24.3\%);

3. Management of arrhythmia (13.5\%);

4. Management of circulation issues other than arrhythmia $(10.8 \%)$;

5. Newborn care (5.4\%) and situations with lack of support by experienced colleagues (5.4\%).

Nurses, 37 responses:

1. Situations with lack of support by physicians (27.0\%);

2. Resuscitation (24.3\%);

3. Teamwork with inexperienced physicians (21.6\%);

4. Respiratory failure (16.2\%);

5. Arrhythmia (5.4\%).

What went good during previous emergencies Physicians, 35 responses:

1. Teamwork between medical and nursing staff (51.4\%);

2. Teamwork with the intensive care unit (ICU) team (25.7\%);

3. Support by consultants (17.1\%);

4. Team communication $(2.9 \%)$;

5. Sufficient in-house emergency structures (2.9\%).

Nurses, 75 responses:

1. Teamwork between medical and nursing staff (60.0\%);

2. Distinct delegation of tasks and/or roles during emergency situations (14.7\%);

3. Teamwork with the ICU team (12.0\%);

4. Sufficient coordination within emergency situations (9.3\%);

5. Sufficient in-house emergency structures (2.7\%).

What could have been better during previous emergencies Physicians, 38 responses:

1. Own lack of preparedness (39.5\%);

2. Deficient in-house emergency structures (28.9\%);

3. Deficient team communication (18.4\%);

4. Lack of experienced support (7.9\%);

5. Deficient equipment (5.3\%).
Nurses, 34 responses:

1. Deficient coordination within emergency situations (41.2\%);

2. Own lack of preparedness (23.5\%);

3. Deficient team communication (11.8\%);

4. Lack of experienced support (11.8\%);

5. Deficient equipment (11.8\%).

\section{Previous training}

Self-directed learning played the major role in knowledge acquisition for physicians, whereas it was negligible for nurses, see Fig. 1. Attendance of practical courses for acquiring skills related to pediatric emergencies was low among physicians; only $32 \%$ had previously attended one or more courses. Course attendance was distinctly more common among nurses for acquiring both knowledge and skills ( $76 \%$ and $68 \%$, respectively). On-the-job training for knowledge and skill acquisition was important for both medical and nursing staff.

\section{Individual needs assessment}

Agreements to a certain level of knowledge and skills differed significantly concerning pediatric emergencies,

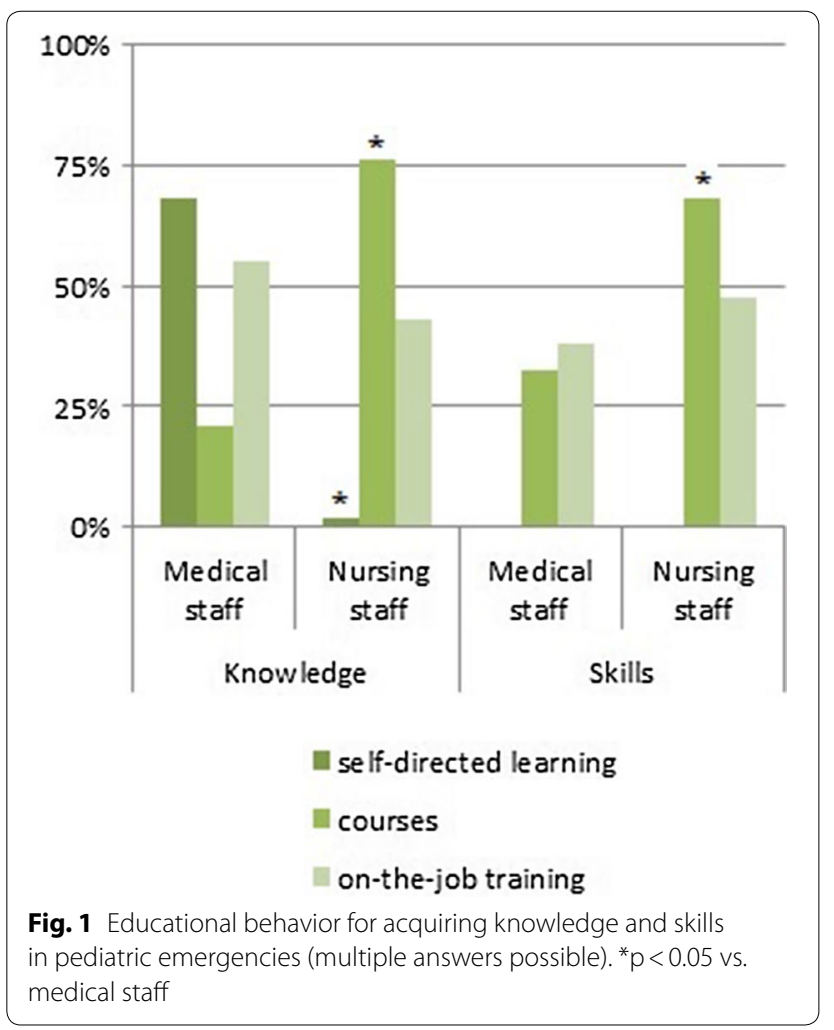




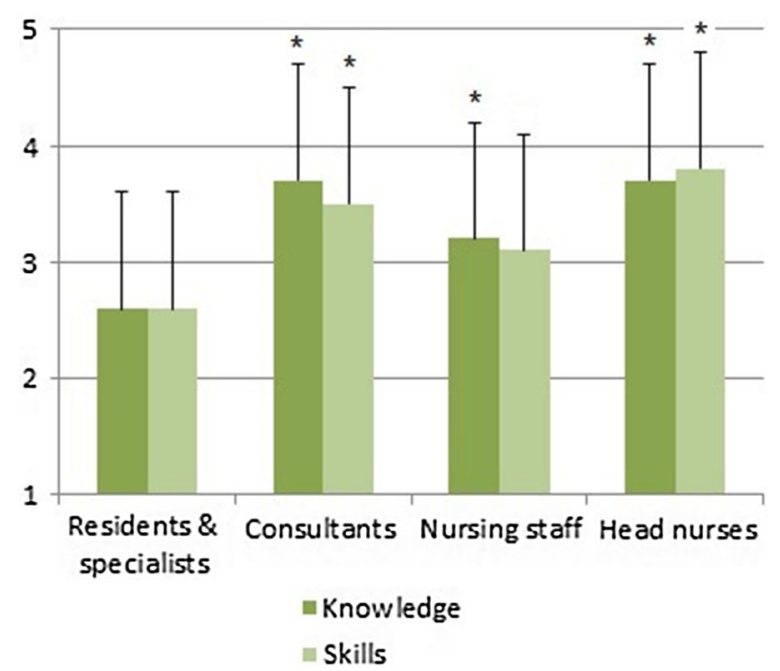

Fig. 2 Agreements for having adequate knowledge and skills concerning pediatric emergencies. Agreements on Likert scale from 1 (totally disagree) to 5 (totally agree); ${ }^{*} p<0.05$ vs. residents and specialists

see Fig. 2 (knowledge $F(3,123)=6.647, \mathrm{p}<0.001$; skills $F(3,123)=5.832, \quad \mathrm{p}=0.001)$. For individual training needs, see Table 1. Furthermore, physicians mentioned traumatology (two answers) as being an additional training need.

\section{Discussion}

Physicians and nurses similarly ranked types of emergencies, and particularly communication and collaboration issues were perceived as either positive or problematic. Educational strategies differed distinctly between professions; nurses did often attend practical courses, whereas physicians tended to self-directed learning. Self-assessed knowledge and skills for pediatric emergencies were moderate for both, medical and nursing staff, but slightly higher among nurses. Self-identified individual training needs were high for both physicians and nurses, especially for basic procedures and frequently required emergency algorithms.

Both physicians and nurses reported the same types of emergencies as most frequently experienced. This is comparable to the pediatric emergency prevalence reported by others [23, 24]. Resuscitation situations were judged the most precarious for both professions. Remarkably, resuscitation happens rarely on peripheral wards outside of the ICU, but has obviously left strong impressions.

Physicians reported more frequently than nurses that their own emergency preparedness caused feelings of insecurity. In contrast, nurses mentioned aspects of teamwork as the most frequent cause of feeling insecure.
These responses might be related to differences in clinical experience between medical and nursing staff; the nurses in this survey had significantly more clinical experience. Teamwork and communication are key factors in successfully managing emergency situations $[7,8]$, and this assertion was supported by our results; both physicians and nurses reported positive experiences regarding teamwork in previous emergency situations. Well-organized coordination and a clear distribution of roles in emergency situations appear to be important, especially for nurses [8].

The previous training of physicians and nurses differed considerably in our study. Physicians frequently used self-directed learning, which was unusual among nurses. Typically, physicians make active choices in how and what to learn from a diversity of offers, as a part of continuing medical education, rather than using standardized programs [25]. In contrast, nurses frequently attended practical courses. Wisniewski et al. found that face-to-face sessions and online web-courses were the preferred educational methods for nurses [19] - both guided forms of learning.

For self-reported preparedness, participants reported moderate levels of knowledge and skills for pediatric emergencies, with the lowest ratings by residents. This is comparable with other evaluation findings in residency programs $[20,26]$ and it is worth mentioning that residents tend to have lower self-confidence in their skills and knowledge than nurses [27]. However, high confidence does not necessarily lead to sufficient performance in real emergency encounters, as shown by Nadel et al. [3]. In our study, there were no significant differences in self-rated knowledge and skills within all professional groups.

When discussing their training needs in more detail, participants broadly agreed that training in procedures and algorithms is required; this is, again, similar to other reports [18, 28-30]. Both, physicians and nurses, reported training in basic procedures, such as pediatric basic life support, bag-valve-mask ventilation and most emergency algorithms as of the highest need. The greatest differences in training needs between physicians and nurses were for intravenous access, newborn life support and metabolic emergencies, which were all considered of high need by physicians but not nurses. As described above, venous access is a physician activity at the study site. In addition, most nurses do not work in specialized neonatal wards, and physicians usually have neonatal placements during their residencies. Metabolic emergencies are uncommon at most peripheral wards; they are more common at specialized wards and ICUs, and can be more often encountered by physicians during their residency placements. Both physicians and nurses identified 
team communication as core aspect to their emergency training.

To achieve pediatric emergency preparedness, many different approaches have been described, but often without evaluation of their short- and long-term outcomes [31]. Recent data highlight the value of simulation-based training for teams in acquiring technical and non-technical skills [12, 28, 32, 33]. Therefore small-group teaching is necessary and provides a controlled environment in which repetitive practice with close supervision is supported [34-36]. However, this type of training is expensive in terms of equipment and human resources [6]. To increase the effectiveness and efficiency of such training, a blended learning approach might be promising, with tailored preparation for each profession. There are positive reports on using such blended methods to teach clinical procedures to undergraduates [37]. Such an approach may specifically address the different learning behaviors and needs of nurse and physician groups, and subsequently enhance acceptance. It may also sensitize for inter-professional collaboration with somewhat differing learning objectives between professional groups.

\section{Conclusions}

Differences of profession-specific roles and requirements, as well as in learning behaviors must be taken into account when developing interprofessional team trainings.

\section{Limitations}

The data analysis is limited by the use and comparison of means of actually ordinal scaled results (Likert) and so only providing exploratory insights to existing differences between professions.

The given results reflect the subjective perceptions of the staff of one tertiary pediatric center in Germany; thus, they should be interpreted with caution and may not be fully applicable to other pediatric emergency care sites.

\section{Abbreviations \\ ANOVA: analysis of variance; ICU: intensive care unit; LSD: least significant difference.}

\section{Authors' contributions}

$\mathrm{RL}$ and AS carried out the survey, RL performed its analysis and drafted the manuscript. JM compiled and revised the survey and its design. $\mathrm{BH}, \mathrm{GFH}$ and BT participated in its design and coordination. SH conceived of the study, was responsible for its design and helped to draft the manuscript. All authors read and approved the final manuscript.

\section{Author details}

${ }^{1}$ Department of Pediatrics I, Center for Pediatrics and Adolescent Medicine, Im Neuenheimer Feld 430, 69120 Heidelberg, Germany. ${ }^{2}$ Department for Assessment and Evaluation, Institute for Medical Education, Mittelstrasse 43, 3012 Bern, Switzerland.
Acknowledgements

We thank Elisabeth Karmrodt, MD, for her support in data acquisition and analysis.

\section{Competing interests}

The authors declare that they have no competing interests.

\section{Availability of data and materials}

The datasets analyzed during the current study are not publicly available due to participants consent but are available from the corresponding author on reasonable request.

\section{Consent for publication \\ Not applicable.}

\section{Ethics approval and consent to participate}

According to legal requirements, approval was granted by the staff council of the University Hospital, Heidelberg, Germany. In accordance with national guidelines, approval by an ethics committee was neither required nor applied for this type of educational survey. Participation in this study was voluntary and anonymous. Informed consent was obtained from study participants.

\section{Funding}

This work was supported by the Klaus Tschira Stiftung gGmbH (Project No. 00.162.2010) without any involvement in the study design, collection of data, analysis, or reporting of results.

We also acknowledge financial support by Deutsche Forschungsgemeinschaft within the funding programme Open Access Publishing, by the BadenWürttemberg Ministry of Science, Research and the Arts and by RuprechtKarls-Universität Heidelberg.

\section{Publisher's Note}

Springer Nature remains neutral with regard to jurisdictional claims in published maps and institutional affiliations.

Received: 11 October 2018 Accepted: 8 January 2019

Published online: 14 January 2019

\section{References}

1. Hunt EA, Fiedor-Hamilton M, Eppich WJ. Resuscitation education: narrowing the gap between evidence-based resuscitation guidelines and performance using best educational practices. Pediatr Clin North Am. 2008;55(4):1025-50.

2. Hunt EA, Vera K, Diener-West M, Haggerty JA, Nelson KL, Shaffner DH, et al. Delays and errors in cardiopulmonary resuscitation and defibrillation by pediatric residents during simulated cardiopulmonary arrests. Resuscitation. 2009;80(7):819-25.

3. Nadel FM, Lavelle JM, Fein JA, Giardino AP, Decker JM, Durbin DR. Assessing pediatric senior residents' training in resuscitation: fund of knowledge, technical skills, and perception of confidence. Pediatr Emerg Care. 2000;16(2):73-6.

4. Ralston ME, Zaritsky AL. New opportunity to improve pediatric emergency preparedness: pediatric emergency assessment, recognition, and stabilization course. Pediatrics. 2009:123(2):578-80.

5. White JR, Shugerman R, Brownlee C, Quan L. Performance of advanced resuscitation skills by pediatric housestaff. Arch Pediatr Adolesc Med. 1998;152(12):1232-5.

6. Jewkes F, Phillips B. Resuscitation training of paediatricians. Arch Dis Child. 2003;88(2):118-21.

7. Eppich WJ, Brannen M, Hunt EA. Team training: implications for emergency and critical care pediatrics. Curr Opin Pediatr. 2008;20(3):255-60.

8. Sherman JM, Chang TP, Ziv N, Nager AL. Barriers to effective teamwork relating to pediatric resuscitations: perceptions of pediatric emergency medicine staff. Pediatr Emerg Care. 2017. https://doi.org/10.1097/ PEC.0000000000001275.

9. Hunt EA, Walker AR, Shaffner DH, Miller MR, Pronovost PJ. Simulation of in-hospital pediatric medical emergencies and cardiopulmonary 
arrests: highlighting the importance of the first 5 minutes. Pediatrics. 2008;121(1):e34-43.

10. Ten Eyck R. Simulation in emergency medicine training. Pediatr Emerg Care. 2011;27(4):333-41.

11. Yager P, Lok J, Klig J. Advances in simulation for pediatric critical care and emergency medicine. Curr Opin Pediatr. 2011;23(3):293-7.

12. Adler MD, Vozenilek JA, Trainor JL, Eppich WJ, Wang EE, Beaumont JL, et al. Development and evaluation of a simulation-based pediatric emergency medicine curriculum. Acad Med. 2009;84(7):935-41.

13. Bridges DR, Davidson RA, Odegard PS, Maki IV, Tomkowiak J. Interprofessional collaboration: three best practice models of interprofessional education. Med Educ Online. 2011;16:6035. https://doi.org/10.3402/meo. v16i0.6035.

14. Weinstock PH, Kappus LJ, Kleinman ME, Grenier B, Hickey P, Burns JP. Toward a new paradigm in hospital-based pediatric education: the development of an onsite simulator program. Pediatr Crit Care Med. 2005;6(6):635-41.

15. Biarenta D, Binghamb R, Eich C, López-Herced J, Maconochiee I, Rodríguez-Núnez A, et al. European resuscitation council guidelines for resuscitation 2010 section 6. Paediatric life support. Resuscitation. 2010;81(10):1364-88.

16. Walsh-Kelly C, Bergholte J, Erschen M, Melzer-Lange M. Office preparedness for pediatric emergencies: baseline preparedness and the impact of guideline distribution. Pediatr Emerg Care. 2004;20(5):289-94.

17. Shetty AK, Hutchinson SW, Mangat R, Peck GQ. Preparedness of practicing pediatricians in Louisiana to manage emergencies. South Med J. 1998:91(8):745-8.

18. Al-Eissa M, Chu S, Lynch T, Warren D, Seabrook JA, Rieder MJ, et al. Self-reported experience and competence in core procedures among Canadian pediatric emergency medicine fellowship trainees. CJEM. 2008:10(6):533-8

19. Wisniewski R, Dennik-Champion G, Peltier JW. Emergency preparedness competencies: assessing nurses' educational needs. J Nurs Adm. 2004;34(10):475-80

20. Buss PW, McCabe M, Evans RJ, Davies A, Jenkins H. A survey of basic resuscitation knowledge among resident paediatricians. Arch Dis Child. 1993;68(1):75-8.

21. Cook DA, Beckmann TJ. Current concepts in validity and reliability for psychometric instruments: theory and application. Am J Med. 2006:119(2):166.e7-16.

22. Krippendorff K. Content analysis: an introduction to its methodology. 2nd ed. Thousand Oaks: Sage; 2004.

23. Fuchs $\mathrm{S}$, Jaffe DM, Christoffel KK. Pediatric emergencies in office practices: prevalence and office preparedness. Pediatrics. 1989;83(6):931-9.
24. Eich C, Russo SG, Heuer JF, Timmermann A, Gentkow U, Quintel M, et al. Characteristics of out-of-hospital paediatric emergencies attended by ambulance- and helicopter-based emergency physicians. Resuscitation. 2009;80(8):888-92.

25. Norman GR, Shannon SI, Marrin ML. The need for needs assessment in continuing medical education. BMJ. 2004;328(7446):999-1001.

26. Hayes CW, Rhee A, Detsky ME, Leblanc VR, Wax RS. Residents feel unprepared and unsupervised as leaders of cardiac arrest teams in teaching hospitals: a survey of internal medicine residents. Crit Care Med. 2007;35(7):1668-72

27. Rassin M, Avraham M, Nasi-Bashari A, Idelman S, Peretz Y, Morag S, et al. Emergency department staff preparedness for mass casualty events involving children. Disaster Manag Response. 2007;5(2):36-44.

28. Gaies MG, Landrigan CP, Hafler JP, Sandora TJ. Assessing procedural skills training in pediatric residency programs. Pediatrics. 2007;120(4):715-22.

29. Dyson L, Hedgecock B, Tomkins S, Cooke G. Learning needs assessment for registered nurses in two large acute care hospitals in Urban New Zealand. Nurse Educ Today. 2009:29(8):821-8.

30. Hannon FB. A national medical education needs' assessment of interns and the development of an intern education and training programme. Med Educ. 2000;34(4):275-84.

31. Ablah E, Tinius AM, Konda K. Pediatric emergency preparedness training: are we on a path toward national dissemination? J Trauma. 2009;67(2 Suppl):S152-8.

32. Eppich WJ, Adler MD, McGaghie WC. Emergency and critical care pediatrics: use of medical simulation for training in acute pediatric emergencies. Curr Opin Pediatr. 2006;18(3):266-71.

33. Cheng A, Goldman RD, Aish MA, Kissoon N. A simulation-based acute care curriculum for pediatric emergency medicine fellowship training programs. Pediatr Emerg Care. 2010;26(7):475-80.

34. Issenberg SB, McGaghie WC, Petrusa ER, Lee GD, Scalese RJ. Features and uses of high-fidelity medical simulations that lead to effective learning: a BEME systematic review. Med Teach. 2005;27(1):10-28.

35. Ericsson KA. Deliberate practice and the acquisition and maintenance of expert performance in medicine and related domains. Acad Med. 2004;79(suppl):70-81.

36. McGaghie WC, Issenberg SB, Petrusa ER, Scalese RJ. A critical review of simulation-based medical education research: 2003-2009. Med Educ. 2010;44(1):50-63

37. Lehmann R, Thiessen C, Frick B, Bosse HM, Nikendei C, Hoffmann GF, et al. Improving pediatric basic life support performance through blended learning with web-based virtual patients: randomized controlled trial. J Med Internet Res. 2015;17(7):e162.

\footnotetext{
Ready to submit your research? Choose BMC and benefit from:

- fast, convenient online submission

- thorough peer review by experienced researchers in your field

- rapid publication on acceptance

- support for research data, including large and complex data types

- gold Open Access which fosters wider collaboration and increased citations

- maximum visibility for your research: over $100 \mathrm{M}$ website views per year
}

At BMC, research is always in progress.

Learn more biomedcentral.com/submissions 